\title{
1 The Antimicrobial Efficacy Of Plasma Activated Water Is Modulated By Reactor Design And Water Composition
}

Joanna G. Rothwell ${ }^{\mathrm{a}}$, David Alam ${ }^{\mathrm{b}}$, Dee A. Carter ${ }^{\mathrm{a}, \mathrm{c}}$ Behdad Soltani $^{\mathrm{b}}$, , Robyn McConchie $^{\mathrm{a}}$, Renwu Zhou ${ }^{\mathrm{b}}$, Patrick J. Cullen ${ }^{\mathrm{b}}$ and Anne Mai-Prochnow ${ }^{\mathrm{b}}$

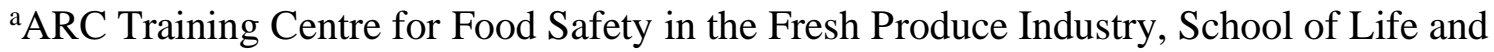

8 Environmental Sciences, Sydney Institute of Agriculture, Faculty of Science, The University

9 of Sydney, New South Wales, Australia

10 bschool of Chemical and Biomolecular Engineering, The University of Sydney, New South

11 Wales, Australia

$12{ }^{\mathrm{c}}$ The Marie Bashir Institute for Infectious Diseases and Biosecurity, University of Sydney,

13 New South Wales, Australia

14 joanna.rothwell@sydney.edu.au, david.alam@sydney.edu.au, dee.carter@sydney.edu.au,

15 behdad.soltani@sydney.edu.au, $\underline{\text { robyn.mcconchie@sydney.edu.au, }}$

16 patrick.cullen@sydney.edu.au, anne.mai-prochnow@sydney.edu.au,

Corresponding author: Renwu Zhou; renwu.zhou@sydney.edu.au and Anne Mai-Prochnow anne.mai-prochnow@sydney.edu.au,

\section{Abstract}

23 Plasma activated water (PAW) contains a cocktail of reactive oxidative species and free radicals and has demonstrated efficacy as a sanitizer for fresh produce, however there is a need for further optimization. The antimicrobial efficacy of PAW produced by a bubble spark discharge (BSD) reactor and a dielectric barrier discharge-diffuser (DBDD) reactor operating at atmospheric conditions with air, discharge frequencies of 500, 1000 and $1500 \mathrm{~Hz}$, and MilliQ and tap water, was investigated with model organisms Listeria innocua and Escherichia coli. Optimal conditions were subsequently employed for pathogenic bacteria Listeria monocytogenes, E. coli and Salmonella enterica. PAW generated with the DBDD reactor reduced more than 6$\log$ CFU of bacteria within 1 minute of treatment. The BSD-PAW, while attaining high CFU reduction was less effective, particularly for L. innосиа. Analysis of physicochemical properties revealed BSD-PAW had a greater 
33 reactive species, including the short-lived superoxide $\left(\cdot \mathrm{O}_{2}^{-}\right)$radical that could not be directly measured in the

34 PAW. This demonstrated a critical role of superoxide for the inactivation of both E. coli and L. innocua by

35 DBDD-PAW, while in BSD-PAW it had a role in L. innocua inactivation only. Overall, this study demonstrates

36 the potential of DBDD-PAW in fresh produce, where there is a need for sterilization while minimizing chemical

37 inputs and residues and maintaining food quality. Highly effective PAW was generated using air as a processing gas and tap water, making this a feasible and cost-effective option.

\section{Importance}

41 There is a growing demand for fresh food produced with minimal processing, however guaranteeing microbial safety in the absence of a thermal kill step is challenging. Plasma-activated water (PAW) is a promising novel

43 antimicrobial but its use in high-risk applications like the sanitization of fresh produce requires further optimization. This study demonstrated the importance of reactor design in the production of reactive species in PAW with capacity to kill bacteria. Very effective PAW was generated using a dielectric barrier dischargediffuser (DBDD) system, with antimicrobial activity attributed to the presence of superoxide radicals. The DBBD reactor used air as a processing gas and tap water, highlighting the potential of this approach as a costeffective and green alternative to chemical treatment methods that are currently used in food decontamination.

\section{Keywords:}

51 cold atmospheric-pressure plasma, plasma-activated water, bacterial inactivation, reactive oxygen and nitrogen species, food safety, dialectic barrier discharge, spark discharge, superoxide 


\section{Introduction.}

55 Developing safe and effective antimicrobial technologies is of great importance in many areas where unwanted 56 microbial growth can occur, including medical, water and food industries. Plasma activated water (PAW) is a promising antimicrobial tool with a wide variety of potential applications that reduce the need for toxic chemicals. Of particular interest is the application of PAW in fresh produce processing, since current disinfection methods rely on chemicals that have significant health and environmental impacts. PAW has been shown to reduce pathogenic microbes with relevance to fresh produce safety, including Escherichia coli $(1,2)$, Staphylococcus aureus (3-7), Bacillus. subtilis (8), Listeria monocytogenes and Salmonella Typhimurium (9), while retaining product quality (10).

PAW can be produced from cold plasma, a non-thermal plasma composed of highly energetic particles including UV, charged ions, accelerated electrons, radical species, excited molecules and atoms $(11,12)$. Cold plasma discharged over the surface of water or directly ignited within water results in plasma-liquid interactions that generate various reactive species with antibacterial activity (13). These include reactive oxygen species, such as hydroxyl radicals $(\cdot \mathrm{OH})$, atomic oxygen, superoxide $\left(\mathrm{O}_{2}^{-}\right)$, ozone $\left(\mathrm{O}_{3}\right)$ and hydrogen peroxide $\left(\mathrm{H}_{2} \mathrm{O}_{2}\right)$, as well as reactive nitrogen species including atomic nitrogen, peroxynitrite, nitric oxide, nitrates $\left(\mathrm{NO}_{3}^{-}\right)$and nitrites $\left(\mathrm{NO}_{2}^{-}\right)$(14). While most reactive species are extremely short-lived, nitrite, nitrate and hydrogen peroxide are relatively stable and can last several months depending on storage conditions; for example they can be preserved by freezing $(6,11)$. PAW has an acidic $\mathrm{pH}$ due to hydrogen peroxide, nitric and peroxynitrous acid, and a high oxidation-reduction potential (ORP) largely due to hydrogen peroxide $(1,15)$. The individual and synergistic effects of these physicochemical properties and the reactive species in this dynamic mixture, make it potently antimicrobial (16).

There are multiple PAW configurations that have been described in depth (13). To date, the most common configuration to produce PAW has been to discharge gaseous plasma across water surfaces (17), but this confers a relatively poor transfer of reactive species. More recent configurations use multiphase discharges where plasma gas is bubbled through water, allowing a substantially greater transfer of reactive species into the water. Two such methods are shown in Figure 1. The bubble spark discharge (BSD) transmits reactive species into the water via high-intensity spark plasma that creates reactive species at the plasma-water interface, in conjunction with plasma gas bubbles that diffuse reactive species into the water. In the dialectic barrier discharge diffusor 
84 (DBDD), the reactor produces a larger volume of lower energy DBD plasma that is introduced into the solution The body of the BSD reactor consisted of a $175 \mathrm{~mm}$-length quartz tube (10 mm outside diameter (OD) and 1.5 via a diffusor, producing copious small bubbles with a large surface area to allow mass transfer of reactive species into solution. Different discharge schemes can be employed to regulate the concentration and types of reactive species generated in PAW (18). However, further research is required to understand how to maximize the production of reactive species using the different plasma reactor designs and to determine how these work to inhibit and kill bacterial cells.

The current study set out to compare BSD and DBBD PAW systems for their antimicrobial efficacy against representative bacterial food pathogens. While most PAW research has used sterile distilled and deionized water (19), we also tested tap water as a more economically viable option for food processing. We then quantified the reactive species produced by the different systems and used selective quenching agents to determine which reactive species contributed most to the antimicrobial activity.

\subsection{Materials and Methods}

\subsection{Plasma reactor design}

BSD and DBDD reactors were designed in-house (Plasmaleap Technologies, Sydney, Australia) using the setup shown in Figure 1. For both reactors, power was supplied by a high voltage micropulse generator Leap100 (PlasmaLeap Technologies, Sydney, Australia), capable of providing a high voltage pulse of up to $80 \mathrm{kV}$ (p-p), a repetitive pulse frequency from 100 to $3000 \mathrm{~Hz}$, and maximum output power of $400 \mathrm{~W}$. Both reactors used stainless steel high voltage electrodes fitted in place by machined acrylic spacers and polytetrafluoroethylene (PTFE) tee fittings. The PTFE tee fitting connected to the open end of the dispersion tube in both reactors, and was used to supply the airflow into the tubes as well as to support the electrode. A rotameter to control the airflow rate was attached to a machined Teflon fitting on the outside tubes. The high voltage electrode from the high voltage supply was connected directly to the stainless steel electrode, whereas the ground electrode consisted of a stainless steel plate under the bottle connected to the ground wire from the power supply. Both reactors were placed into $250 \mathrm{~mL}$ Schott bottles filled with autoclaved tap or MilliQ water. $\mathrm{mm}$ wall thickness) with one end sealed. Four $0.4 \mathrm{~mm}$ holes were positioned radially approximately $5 \mathrm{~mm}$ 
113 above the sealed end. The electrode was a stainless steel rod (4 mm OD) inserted coaxially along the length of

114 the quartz tube. The DBDD reactor employed a conventionally coaxial electrode configuration connected to a

115 glass diffusor to transfer the reactive gas species generated in the plasma into the water. The body of the DBDD

116 reactor consisted of a $150 \mathrm{~mm}$ long gas dispersion tube with a fritted glass tip with a pore size $10-20 \mu \mathrm{m}($ Ace

117 Glass 720208$)$. A sealed borosilicate tube ( $\approx 4 \mathrm{~mm}$ OD, $0.8 \mathrm{~mm}$ wall thickness) was used as a dielectric insulator

118 to sheath the high voltage electrode inside the length of the dispersion tube.

\subsection{Bacterial cultures}

121 The bacterial species used in this study are listed in Table 1. Model non-pathogenic surrogate species Listeria innocua (ICMPR:80-16-328-502) and E. coli (ATCC R25922) were used to observe the antimicrobial activity of PAW under different plasma conditions. These conditions were then applied to isolates of pathogenic bacteria linked to foodborne illness cases, which were sourced from the New South Wales Enteric Reference Laboratory at the Centre for Infectious Diseases and Microbiology Laboratory Services (CIDMLS), NSW Health Pathology, Westmead. Bacteria were resuscitated from glycerol stocks stored at $-80{ }^{\circ} \mathrm{C}$ using tryptic soy agar (TSA: $17 \mathrm{~g} \mathrm{~L}^{-1}$ pancreatic digest of casein, $5 \mathrm{~g} \mathrm{~L}^{-1}$ Papaic digest of soybean meal, $5 \mathrm{~g} \mathrm{~L}^{-1}$ sodium chloride, $15 \mathrm{~g}$ $\mathrm{L}^{-1}$ agar-agar) plates for Salmonella spp. and E. coli and tryptic soy sheep blood agar (TSBA: TSA with $5 \%$ defibrinated sheep's blood) for Listeria spp., and incubated at $37{ }^{\circ} \mathrm{C}$ overnight. A single colony was then inoculated into $10 \mathrm{~mL}$ of tryptic soy broth (TSB, $17 \mathrm{~g} \mathrm{~L}^{-1}$ pancreatic digest of casein, $2.5 \mathrm{~g} \mathrm{~L}^{-1} \mathrm{D}(+) \mathrm{glucose}$ monohydrate, $3 \mathrm{~g} \mathrm{~L}^{-1}$ Papaic digest of soybean meal, $5 \mathrm{~g} \mathrm{~L}^{-1}$ sodium chloride, $2.5 \mathrm{~g} \mathrm{~L}^{-1}$ di-potassium hydrogen phosphate) for 24 hours with shaking at $30^{\circ} \mathrm{C}$ for Listeria spp. and $37^{\circ} \mathrm{C}$ for Salmonella spp and E. coli. $10 \mu \mathrm{L}$ from each suspension was then transferred into $10 \mathrm{~mL}$ of TSB and incubated under the same conditions for 18 hours. Cultures were harvested by centrifugation at $3000 \mathrm{rpm}$ for 10 minutes at $4{ }^{\circ} \mathrm{C}$ and the cell pellet was resuspended in a volume of PBS to obtain a concentration of $\sim 1 \times 10^{8} \mathrm{CFU} \mathrm{mL} \mathrm{m}^{-1}$. The final inoculum was stored at $4{ }^{\circ} \mathrm{C}$ and used within 4 hours. The final concentration was verified by back-plating, where Listeria solutions were spread onto TSBA and incubated for $48 \mathrm{~h}$ at $30^{\circ} \mathrm{C}$, and E. coli was spread onto TSA and incubated for 24 h at $37^{\circ} \mathrm{C}$.

\subsection{Bacterial Inhibition by PAW}

141 The inhibition assay was first optimized using non-pathogenic bacteria. For both reactors we tested three different discharge frequencies $(500,1000$ and $1500 \mathrm{~Hz})$ using either autoclaved tap water or Milli-Q water. Air 
143 provided to the reactors at 1 standard liter per minute (SLM) and plasma treatments were performed within a

144 fume hood. For the BSD reactor, a $100 \mu \mathrm{L}$ aliquot of each inoculum prepared as above was pipetted into 100

$145 \mathrm{~mL}$ of MilliQ or tap water in the $250 \mathrm{~mL}$ Schott bottle (figure 1). The setting used on the power supply for the

146 BSD were $150 \mathrm{~V}, 100 \mu$ s duty cycle $60 \mathrm{kHz}$ resonance frequency. For the DBDD reactor, $200 \mu \mathrm{L}$ of the

147 inoculum was pipetted into $200 \mathrm{~mL}$ of Milli-Q or tap water in the $250 \mathrm{~mL}$ Schott bottle. The power supply

148 settings used were the same as those used with the BSD reactor except voltage, which was 120 V. Different

149 volumes of water were used in the two reactor systems, as the BSD reactor generates a higher intensity plasma

150 and requires a low volume of water to concentrate the reactive species, while the DBDD reactor requires a

151 larger volume to provide a greater surface area for the bubbles to exchange reactive species with the water. Both reactors were run for 12.5 minutes with samples removed at 1, 2.5, 5 7.5, 10 and 12.5 minutes. A control was

153 included for both reactors where the same volume of water and inoculum were bubbled under identical airflow conditions for 12.5 minutes without the power source turned on. Each treatment was neutralized after plasma exposure by dilution into a modified Dey-Engley neutralizing broth $\left(5 \mathrm{~g} \mathrm{~L}^{-1}\right.$ pancreatic digest of casein, $2.5 \mathrm{~g} \mathrm{~L}^{-1}$ yeast extract, $10 \mathrm{~g} \mathrm{~L}^{-1} \mathrm{D}(+)$ glucose monohydrate, $5 \mathrm{~g} \mathrm{~L}^{-1}$ polysorbate $80,7 \mathrm{~g} \mathrm{~L}^{-1}$ lecithin, $6 \mathrm{~g} \mathrm{~L}^{-1}$ sodium thiosulfate, $2.5 \mathrm{~g} \mathrm{~L}^{-1}$ sodium bisulfite). Surviving bacteria were serially diluted in a 96-well plate with $0.1 \%$ peptone water and enumerated using spread plates as above. All experiments were performed in duplicate, with three biological replicates performed on three separate days. (Table 1) were tested using the DBDD reactor with tap water at $1000 \mathrm{~Hz}$ and $120 \mathrm{~V}$ for 1 and 2 minutes.

\subsection{Measurement of PAW Composition}

165 Concentrations of ozone $\left(\mathrm{O}_{3}\right)$, hydrogen peroxide $\left(\mathrm{H}_{2} \mathrm{O}_{2}\right)$, nitrite $\left(\mathrm{NO}_{2}^{-}\right)$and nitrate $\left(\mathrm{NO}_{3}^{-}\right)$along with pH, temperature and conductivity were assessed in the PAW produced by the BSD and DBDD reactors over 12.5

167 min. Ozone was measured using a Hanna Instrument multiparameter photometer (H183399, Rhode Island USA) with colorimetric ozone kits. $\mathrm{H}_{2} \mathrm{O}_{2}$ was measured by a titanium sulfate method (20). Nitrite $\left(\mathrm{NO}_{2}^{-}\right)$was assessed using the Griess Reagent method (21), and nitrate was quantified by High-Pressure Liquid Chromatography

170 (HPLC) using a Shimadzu Prominence-i HPLC system equipped with a photodiode array detector. A YMC-

171 Pack C18 column $(4.6 \mathrm{~mm} \times 250 \mathrm{~mm}, 5 \mu \mathrm{m})$ operated at $40{ }^{\circ} \mathrm{C}$ was used with a mobile phase of 10:90 of methanol/0.1\% acetic acid (22) in Milli-Q water at a flow rate of $0.5 \mathrm{~mL} \mathrm{~min}^{-1}$ for $10 \mathrm{~min}$ with a $10 \mu \mathrm{L}$ 
injection volume. The concentration of nitrate was measured at an absorbance of $200 \mathrm{~nm}$, with a calibration

174 curve plotted by measuring absorbance of a series of standard solutions at $1,5,10,25,30,40,50,60,100 \mathrm{mg} / \mathrm{L}$.

175 PAW samples were initially passed through a filter syringe ( $13 \mathrm{~mm}$ diameter, $0.45 \mathrm{um}$ pore size) before HPLC

176 analysis. Temperature was measured using a Tinytag TGP-4200 Data Logger (Gemini, United Kingdom) with

177 corresponding SWCD-0040: Tinytag Explorer software. pH was measured using a SevenCompact S220 pH

178 meter (Mettler-Toldeo, Switzerland). Conductivity of PAW was measured using a four-ring conductivity probe

179 (HI76312) connected to the Hanna Instrument multiparameter photometer (H183399, Rhode Island, USA).

180 Optical emission spectra (OES) measurements were recorded for both reactors using an Andor Shamrock SR-

181 500i-A-R spectrometer. This emission spectroscopy technique determines how much of an individual excited

182 atom or ion is present in a plasma via the characteristic wavelengths of electromagnetic radiation emitted by

183 individual species. Typical spectra emitted from different reactors were used to investigate the main excited

184 active species generated by air plasma ranging from 200 to $900 \mathrm{~nm}$. The optical fiber was located at the DB

185 section in the DBDD reactor or at the same level as the bubble-liquid interface in the BSD reactor. Chemical

186 analysis of the tap water was performed by Envirolab Sevices (Sydney, Australia), where the following water

187 properties were assessed: $\mathrm{pH}$, electrical conductivity, total dissolved solids, ionic balance (calcium, potassium,

188 magnesium, sodium, hardness, hydroxide alkalinity, bicarbonate alkalinity, carbonate alkalinity, total alkalinity,

189 chloride, sulfate), fluoride, nitrate, nitrite, total metals (arsenic, cadmium, copper, lead, manganese, iron) and

190 dissolved iron.

191

\section{$192 \quad 2.5$ Scavenger Assay}

193 Chemical scavengers were used to specifically quench reactive species generated in the PAW to investigate

194 their roles in antimicrobial activity. Scavenger types and concentrations were selected based on previous studies 195 in PAW and included $20 \mu \mathrm{M}$ hemoglobin for nitric oxide (NO) (23), $200 \mathrm{mM}$ mannitol for hydroxide (·OH)

196 (24), $10 \mathrm{mM}$ sodium pyruvate for hydrogen peroxide $\left(\mathrm{H}_{2} \mathrm{O}_{2}\right)(21) 100 \mathrm{uM}$ Uric acid for ozone $\left(\mathrm{O}_{3}\right)(21)$ and 20

$197 \mathrm{mM}$ tiron for superoxide ion $\left(\cdot \mathrm{O}_{2}^{-}\right)(24)$ (Sigma-Aldrich, Missouri, United States).

199 Scavenger solutions and bacterial suspensions at a final concentration of $\sim 1 \times 10^{\wedge} 5$ cells $/ \mathrm{mL}$ (section 2.1 ) were 200 added to the water in the $250 \mathrm{~mL}$ Schott bottle prior to plasma activation. Reactor conditions were selected for 201 the scavenger assay based on the results of antimicrobial activity analysis, such that there was either a complete reduction of bacteria, or if this was not achieved the longest run time with the highest discharge frequency was 
used. For the BSD reactor, for L. innocua this was $1500 \mathrm{~Hz}$ for $5 \mathrm{~min}$ in milli-Q or for $13.5 \mathrm{~min}$ in tap water, and for E. coli it was $1500 \mathrm{~Hz}$ for $2 \mathrm{~min}$ in milli-Q or for $12.5 \mathrm{~min}$ in tap water. For the DBDD reactor, $1000 \mathrm{~Hz}$ for 1 min was used for both water types and both bacteria. After plasma treatment, aliquots of the solutions were removed and immediately neutralized in DE broth before being serially diluted and plated out as described above (section 2.1).

208

\section{6 Statistical analysis}

210 Two-way ANOVAs followed by Dunnett's multiple comparisons tests comparing the PAW treatments to the 211 water controls (Fig. 2) or comparing scavenger treatments to the no scavenger PAW condition (Fig. 6) were 212 performed using GraphPad Prism version 8.0.0 (GraphPad Software, San Diego, California USA). A p-value of $213<0.05$ was considered statistically significant.

\subsection{Results}

\subsection{PAW generated using BSD or DBDD reactors with Milli-Q or tap water is} antibacterial with variable efficacy

The two different plasma generating probes (Fig. 1) were compared for their ability to reduce CFU numbers of E. coli and L. innocua using either milliQ or tap water (Fig. 2). Chemical analysis of tap water indicated a variety of different inorganic ions were present, including trace amounts of various metals (supplementary table 1). PAW generated by the DBDD reactor (PAW-DBDD) was the most effective, achieving a complete (6-log) reduction of both bacterial species within 1 minute with both tap and MilliQ water and across all discharge frequencies. PAW produced by the BSD reactor (BSD-PAW) did not reduce the bacterial load as rapidly as the DBDD-PAW under any of the conditions tested, and more variability was observed across treatments. In all cases, the $1500 \mathrm{~Hz}$ discharge frequency was the most effective, and CFU were reduced more rapidly using MilliQ than tap water. Treatment response also varied by bacterial species: BSD-PAW generated using MilliQ water reduced E. coli counts by $6 \log$ in 2.5 minutes at 1000 or $1500 \mathrm{~Hz}$, and in 5 minutes at $500 \mathrm{~Hz}$, while it took an additional 2.5 minutes to achieve the same reduction of $L$. innocua. For the BSD-PAW generated using 
232 As DBDD-PAW was clearly more efficacious, six foodborne pathogenic bacteria that have caused severe

233 disease in humans (Table 1) were tested using this system at $1000 \mathrm{~Hz}, 120 \mathrm{~V}$ with tap water. All six bacterial

234 strains were completely inactivated $(6 \log )$ within 1 minute (Fig. 3).

\subsection{Physicochemical properties of PAW varied with reactor design, generation}

conditions, and water type

The physicochemical properties of the plasma and the PAW were assessed for each reactor. Optical emission spectra (OES) were used to determine the main excited active species generated by each type of plasma in the air. As these initial short-lived species are highly reactive and cause downstream reactions that result in the

242 generation of other secondary species, the characterization of OES is critical for defining the physicochemical properties of the PAW. The OES obtained from the DBDD, and BSD reactors ranged from 200 to $900 \mathrm{~nm}$ and

244 had large nitrogen emission peaks, indicating that high levels of excited nitrogen molecules and ions were present (Fig. 4). Excited oxygen emission peaks were observed for both reactors, with slightly higher peaks for the BSD reactor. Hydroxy $(\cdot \mathrm{OH})$ emission peaks were only observed in the plasma produced by the BSD reactor.

Reactive species produced in PAW over time were quantified using the same parameters that had been applied in the tests for antibacterial activity (Fig. 5). PAW generated by the BSD reactor contained higher concentrations of all reactive species tested than DBDD-PAW. In BSD-PAW, all measured reactive species increased over time, while in DBDD-PAW, only $\mathrm{NO}_{3}{ }^{-}$and small amounts of $\mathrm{O}_{3}$ were recorded. For $\mathrm{O}_{3}$, the BSD-PAW had maximum measurable concentrations of $\sim 2 \mathrm{mg} / \mathrm{L}$ and levels increased with the reactor discharge

254 frequency, while the DBDD-PAW had substantially lower amounts of $\mathrm{O}_{3}$ and the lowest discharge frequency produced the highest $\mathrm{O}_{3}$ levels with both tap and Milli-Q water. $\mathrm{H}_{2} \mathrm{O}_{2}$ and $\mathrm{NO}_{2}^{-}$were not present in DBDDPAW, while in the BSD-PAW these reactive species increased linearly with BSD activation time. $\mathrm{NO}_{3}{ }^{-}$ increased linearly over time in PAW generated by both reactors, with the highest discharge frequency producing the highest levels. The physicochemical properties of the PAW produced by the two reactors also differed. The $\mathrm{pH}$ of BSD-PAW was lower than DBDD-PAW, while the temperature and conductivity of BSD-PAW were higher. Overall, the physicochemical properties of BSD-PAW appeared more extreme than the DBDD-PAW. 
262 The water used in the generation of PAW strongly affected its properties. $\mathrm{pH}$ decreased rapidly when Milli-Q

263 water was used, while it remained stable with the use of tap water (Fig. 5). Temperature was not affected by

264 water type, however it became substantially higher in the DBS reactor and increased with discharge frequency.

265 Conductivity was also more affected in MilliQ than tap water, particularly with the DBS reactor.

\subsection{The scavenging of superoxide led to survival of bacteria in DBDD-PAW}

268 To test the role of some of the individual reactive species present in PAW, including some that could not be

269 directly measured, we used a range of scavengers to selectively remove particular species, including tiron

270 (which scavenges superoxide), mannitol (hydroxyl radical), uric acid (ozone), hemoglobin (nitric oxide) and

271 sodium pyruvate (hydrogen peroxide). The addition of tiron led to significantly increased survival of $L$. innocua

272 in both the BSD-PAW and the DBDD-PAW, and increased E. coli survival in DBDD-PAW. There was no

273 significant difference in the scavenging results for the PAW generated in Milli-Q or tap water for both reactors.

274 None of the other scavengers affected the survival of the bacterial pathogens.

\subsection{Discussion}

276 This study compared the efficacy of PAW generated by two novel plasma reactors against foodborne organisms.

277 PAW generated using the DBDD reactor clearly displayed more rapid and acute antimicrobial activity than the

278 BSD-PAW. The DBDD-PAW led to a 6-log reduction of all pathogenic and non-pathogenic bacteria tested within 1 minute, and this occurred with both tap and Milli-Q water (Fig. 2). In contrast, using the BSD-PAW, a

280 6- $\log$ reduction of E. coli and L. innocua in Milli-Q water took 2.5 and 5 minutes, respectively. Tsoukou et. al.

281 (25), who employed a system where the plasma was generated $5 \mathrm{~mm}$ above deionized water, also reported

282 greater bactericidal activity of PAW generated using a dialectic barrier discharge system compared to a spark

283 discharge system.

285 Analysis of the reactive species produced in PAW found these were very different between the two reactors,

286 with fewer types and lower levels of measured reactive species in the DBDD-PAW despite its greater antimicrobial power (Fig. 5). However, the addition of tiron completely quenched the antibacterial activity of the DBDD-PAW (Fig. 6), indicating that superoxide ions and/or downstream reactions from this reactive species were primarily responsible for its powerful antimicrobial activity. Trion selectively interacts with and is oxidized by superoxide, allowing its effective removal from the solution $(26,27)$. Our finding is supported by 
291 previous research showing that superoxide anions and downstream reactive species such as singlet molecular

292 oxygen are significant contributors to the antimicrobial activity of PAW produced by dialectic barrier discharge

293 against yeast cells (28) and Salmonella Typhimurium (29).

295 When PAW was made with the BSD reactor, the addition of tiron lead to increased but not complete survival of

296 L. innocua, indicating that superoxide contributes to the ability of BSD-PAW to kill Listeria, but it is not as

297 critical as in DBDD-PAW. With BSD-PAW there were no distinct scavengers that sequestered antimicrobial

298 activity against $E$. coli. Other reactive species that could not be elucidated in this study, or synergy between

299 components of the complex mixture present in BSD-PAW, may have been responsible for its bactericidal

300 activity. In addition, recent studies suggest that plasma treatment elicits physical conditions, including electric

301 fields (30), that were not investigated here. Further research is required to fully understand what causes the

302 biocidal effects of BSD-PAW.

303

304 The analysis of reactive species present in the PAW highlighted the diversity of molecular species that can be

305 produced by plasma, particularly when using the spark discharge system. The OES (Fig. 4) varied between the

306 two systems due to the different excited nitrogen and oxygen species generated in the gaseous plasmas, and

307 these correspond to the different profiles of reactive species seen in the PAW (Fig. 5). For example, $\mathrm{H}_{2} \mathrm{O}_{2}$ was

308 only quantified in BSD-PAW (Fig. 5), and this can be attributed to the generation of ·OH radicals (Fig. 4)

309 produced directly at the plasma-water interface of the BSD that diffuse into solution and react to form hydrogen

310 peroxide (31). . Similarly, a higher concentration of $\mathrm{NO}_{2}^{-}$and $\mathrm{NO}_{3}{ }^{-}$were detected in the $\mathrm{BSD}-\mathrm{PAW}$ compared

311 to the DBDD-PAW (Fig. 5) as the BSD reactor generated a higher intensity plasma which is able to form $\mathrm{NO}_{\mathrm{x}}$

312 gases (Fig. 4) that diffuse into the water to produce these reactive nitrogen species in solution. ROS

313 concentrations were also higher in the BSD-PAW. The energetic collisions of electrons with $\mathrm{O}_{2}$ molecules

$314\left(\mathrm{O}_{2}+\mathrm{e}^{-} \rightarrow 2 \mathrm{O}+\mathrm{e}^{-}\right)$account for the formation of $\cdot \mathrm{O}$ radicals (13) at 777.2 and $844.6 \mathrm{~nm}$, which were produced

315 by both reactors but in higher concentrations in the BSD reactor, resulting in higher ROS concentrations in the

316 PAW generated by this reactor (Fig. 5).

318 Our findings have importance for translation in the fresh produce industry. Fresh produce treatment requires

319 high water volumes, however most studies to date on PAW have used distilled or deionized water (32), and

320 there is a paucity of research on the antimicrobial efficacy of tap PAW. Deionising water is not economically 
321 feasible for use in sanitation processes, and our study found Milli-Q water rapidly acidified to a pH of 3-4 (Fig.

322 5) which may damage fresh produce. Water hardness has been shown to affect the active components of PAW,

323 however (33), and as the water used in this study is relatively soft (supplementary data table 1), further work is

324 required to determine whether the antimicrobial activity demonstrated here extends to DBDD-PAW produced

325 using tap water of different quality.

326

327 The BSD-PAW, although less effective than DBDD-PAW in the current study, could still have applications in

328 the food industry. The reactive species produced by this reactor were longer-lived compared to the DBDD-

329 PAW, which largely relied on the short-lived reactive species superoxide, and BSD-PAW may be more suitable

330 for use where there is a delay between PAW generation and use. The reactive species in the BSD-PAW

331 increased linearly over time, and longer activation and treatment times may enhance its antimicrobial power.

332 This could also be further increased by synergizing with existing antimicrobials such as hydrogen peroxide (34)

333 or using different processing gas sources such as oxygen (35).

335 The high efficacy of DBDD-PAW against a variety of pathogenic bacterial strains when made with tap water

336 and air as a processing gas, rather than more expensive gases such as argon or oxygen, indicates the potential of

337 this technology as an economically viable in situ sanitation process. Moving to apply this to produce will

338 introduce new challenges, however, as organic load due to soil or plant exudates may interfere with PAW

339 activity. Determining whether these findings extend to additional pathogenic and spoilage species, including

340 yeasts and molds, is also required. This study lays for foundation for further testing and development of PAW

341 as a cost-effective and non-toxic alternative to methods that are currently used in food decontamination.

\section{Conclusions}

344 PAW is a rapidly emerging technology with many promising applications. This study involved a comparison of 345 the efficacy of novel PAW bubbler reactors in their bactericidal performance in situ using both tap and Milli-Q

346 water. The DBDD reactor produced the most effective PAW, which successfully decontaminated 6-log of

347 pathogenic bacteria in tap water within 1 minute, and superoxide was determined to be a critical reactive species

348 for antimicrobial activity. Different generation conditions and water types produced different reactive species

349 profiles that varied in bactericidal power when using BSD-PAW. Tap water is used in many industrial

350 processes, and the strong bactericidal activity of tap PAW produced by the DBDD reactor provides a valuable 
platform for further research. This study has provided new insight into the potential of PAW as a sanitizing

\section{Conflicts of interest}

Author PJ Cullen is the CEO of PlasmaLeap Technologies, the supplier of the plasma power source and reactors

employed in this study.

\section{Funding}

This research was supported by the Australian Research Council Industrial Transformation Training Centre

University of Sydney.

1. Oehmigen K, Hahnel M, Brandenburg R, Wilke C, Weltmann KD, von Woedtke T. 2010. The role of acidification for antimicrobial activity of atmospheric pressure plasma in liquids. Plasma Processes and Polymers 7:250-257.

2. Traylor MJ, Pavlovich MJ, Karim S, Hait P, Sakiyama Y, Clark DS, Graves DB. 2011. Long-term antibacterial efficacy of air plasma-activated water. Journal of Physics DApplied Physics 44.

3. Ma RN, Wang GM, Tian Y, Wang KL, Zhang JE, Fang J. 2015. Non-thermal plasmaactivated water inactivation of foodborne pathogen on fresh produce. Journal of Hazardous Materials 300:643-651.

4. Zhang Q, Ma RN, Tian Y, Su B, Wang KL, Yu S, Zhang J, Fang J. 2016. Sterilization efficiency of a novel electrochemical disinfectant against Staphylococcus aureus. Environmental Science \& Technology 50:3184-3192.

5. Tian Y, Ma RN, Zhang Q, Feng HQ, Liang YD, Zhang J, Fang J. 2015. Assessment of the physicochemical properties and biological effects of water activated by non-thermal plasma above and beneath the water surface. Plasma Processes and Polymers 12:439-449.

6. Shen J, Tian Y, Li YL, Ma RA, Zhang Q, Zhang J, Fang J. 2016. Bactericidal effects against s-aureus and physicochemical properties of plasma activated water stored at different temperatures. Scientific Reports 6.

7. Vlad IE, Martin C, Toth AR, Papp J, Anghel SD. 2019. Bacterial inhibition effect of plasma activated water. Romanian Reports in Physics 71.

8. Sun P, Wu HY, Bai N, Zhou HX, Wang RX, Feng HQ, Zhu WD, Zhang J, Fang J. 2012. Inactivation of bacillus subtilis spores in water by a direct-current, cold atmosphericpressure air plasma microjet. Plasma Processes and Polymers 9:157-164. 
9. Smet C, Govaert M, Kyrylenko A, Easdani M, Walsh JL, Van Impe JF. 2019. Inactivation of single strains of Listeria monocytogenes and Salmonella typhimurium planktonic cells biofilms with plasma activated liquids. Frontiers in Microbiology 10.

10. Pan YY, Cheng JH, Sun DW. 2019. Cold Plasma-mediated treatments for shelf life extension of fresh produce: a review of recent research developments. Comprehensive Reviews in Food Science and Food Safety 18:1312-1326.

11. Thirumdas R, Kothakota A, Annapure U, Siliveru K, Blundell R, Gatt R, Valdramidis VP. 2018. Plasma activated water (PAW): Chemistry, physico-chemical properties, applications in food and agriculture. Trends in Food Science \& Technology 77:21-31.

12. Niedzwiedz I, Wasko A, Pawlat J, Polak-Berecka M. 2019. The state of research on antimicrobial activity of cold plasma. Polish Journal of Microbiology 68:153-164.

13. Zhou RW, Zhou RS, Wang PY, Xian YB, Mai-Prochnow A, Lu XP, Cullen PJ, Ostrikov K, Bazaka K. 2020. Plasma-activated water: generation, origin of reactive species and biological applications. Journal of Physics D-Applied Physics 53:27.

14. Wende K, von Woedtke T, Weltmann KD, Bekeschus S. 2019. Chemistry and biochemistry of cold physical plasma derived reactive species in liquids. Biological Chemistry 400:19-38.

15. Lukes P, Locke BR, Brisset J-L. Aqueous-phase chemistry of electrical discharge plasma in water and in gas-liquid environments, p 243-308, Plasma Chemistry and Catalysis in Gases and Liquids doi:https://doi.org/10.1002/9783527649525.ch7.

16. Bourke P, Ziuzina D, Han L, Cullen PJ, Gilmore BF. 2017. Microbiological interactions with cold plasma. Journal of Applied Microbiology 123:308-324.

17. Mai-Prochnow A, Zhou RW, Zhang TQ, Ostrikov K, Mugunthan S, Rice SA, Cullen PJ. 2021. Interactions of plasma-activated water with biofilms: inactivation, dispersal effects and mechanisms of action. Npj Biofilms and Microbiomes 7:12.

18. Lukes P, Dolezalova E, Sisrova I, Clupek M. 2014. Aqueous-phase chemistry and bactericidal effects from an air discharge plasma in contact with water: evidence for the formation of peroxynitrite through a pseudo-second-order post-discharge reaction of $\mathrm{H} 2 \mathrm{O} 2$ and $\mathrm{HNO} 2$. Plasma Sources Science \& Technology 23.

19. Herianto S, Hou C-Y, Lin C-M, Chen H-L. 2021. Nonthermal plasma-activated water: A comprehensive review of this new tool for enhanced food safety and quality. Comprehensive Reviews in Food Science and Food Safety 20:583-626.

20. Zhou RW, Zhang TQ, Zhou RS, Wang S, Mei DH, Mai-Prochnow A, Weerasinghe J, Fang Z, Ostrikov K, Cullen PJ. 2021. Sustainable plasma-catalytic bubbles for hydrogen peroxide synthesis. Green Chemistry 23:2977-2985.

21. Zhang $T$, Zhou R, Wang P, Mai-Prochnow A, McConchie R, Li W, Zhou R, Thompson EW, Ostrikov K, Cullen PJ. 2020. Degradation of cefixime antibiotic in water by atmospheric plasma bubbles: Performance, degradation pathways and toxicity evaluation. Chemical Engineering Journal doi:https://doi.org/10.1016/i.cej.2020.127730:127730.

22. Li Y, Whitaker JS, McCarty CLJoCA. 2011. Reversed-phase liquid chromatography/electrospray ionization/mass spectrometry with isotope dilution for the analysis of nitrate and nitrite in water. 1218:476-483.

23. Zhou RW, Zhou RS, Wang PY, Luang BY, Zhang XH, Fang Z, Xian YB, Lu XP, Ostrikov KK, Bazaka K. 2019. Microplasma bubbles: reactive vehicles for biofilm dispersal. Acs Applied Materials \& Interfaces 11:20660-20669. 
24. Guo L, Xu RB, Gou L, Liu ZC, Zhao YM, Liu DX, Zhang L, Chen HL, Kong MG. 2018. Mechanism of virus inactivation by cold atmospheric-pressure plasma and plasmaactivated water. Applied and Environmental Microbiology 84:10.

25. Tsoukou E, Delit M, Treint L, Bourke P, Boehm D. 2021. Distinct chemistries define the diverse biological effects of plasma activated water generated with spark and glow plasma discharges. Applied Sciences 11:1178.

26. Peskin A, Labas $Y$, Tikhonov A. 1998. Superoxide radical production by sponges Sycon sp. FEBS letters 434:201-4.

27. Taiwo FA. 2008. Mechanism of tiron as scavenger of superoxide ions and free electrons. Spectroscopy 22:491-498.

28. Xu HB, Zhu YP, Du MR, Wang YQ, Ju SY, Ma RN, Jiao Z. 2021. Subcellular mechanism of microbial inactivation during water disinfection by cold atmospheric-pressure plasma. Water Research 188:16.

29. Baek KH, Heo YS, Park JY, Kang T, Lee YE, Lim J, Kim SB, Jo C. 2020. Inactivation of Salmonella typhimurium by non-thermal plasma bubbles: exploring the key reactive species and the influence of organic matter. Foods 9.

30. Estifaee P, Su X, Yannam SK, Rogers S, Thagard SM. 2019. Mechanism of E. coli inactivation by direct-in-liquid electrical discharge plasma in low conductivity solutions. Scientific Reports 9:2326.

31. Locke BR, Shih K-Y. 2011. Review of the methods to form hydrogen peroxide in electrical discharge plasma with liquid water. Plasma Sources Science and Technology 20:034006.

32. Izumi H, Nakata $Y$, Inoue A. 2016. Enumeration and identification of coliform bacteria injured by chlorine or fungicide mixed with agricultural water. Journal of Food Protection 79:1789-1793.

33. Lin CM, Chu YC, Hsiao CP, Wu JS, Hsieh CW, Hou CY. 2019. The optimization of plasma-activated water treatments to inactivate Salmonella enteritidis (ATCC 13076) on shell eggs. Foods 8:10.

34. Wu SJ, Zhang Q, Ma RN, Yu S, Wang KL, Zhang J, Fang J. 2017. Reactive radical-driven bacterial inactivation by hydrogen-peroxide-enhanced plasma-activated-water. European Physical Journal-Special Topics 226:2887-2899.

35. Lee K, Paek KH, Ju WT, Lee Y. 2006. Sterilization of bacteria, yeast, and bacterial endospores by atmospheric-pressure cold plasma using helium and oxygen. Journal of Microbiology 44:269-275. 
a) BSD reactor

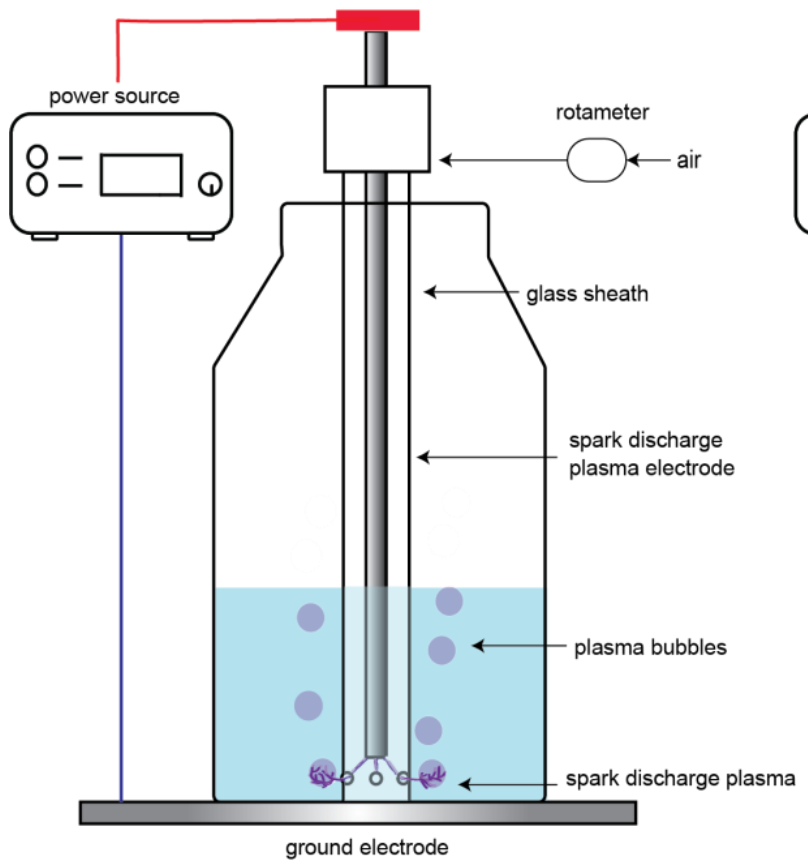

b) DBDD reactor

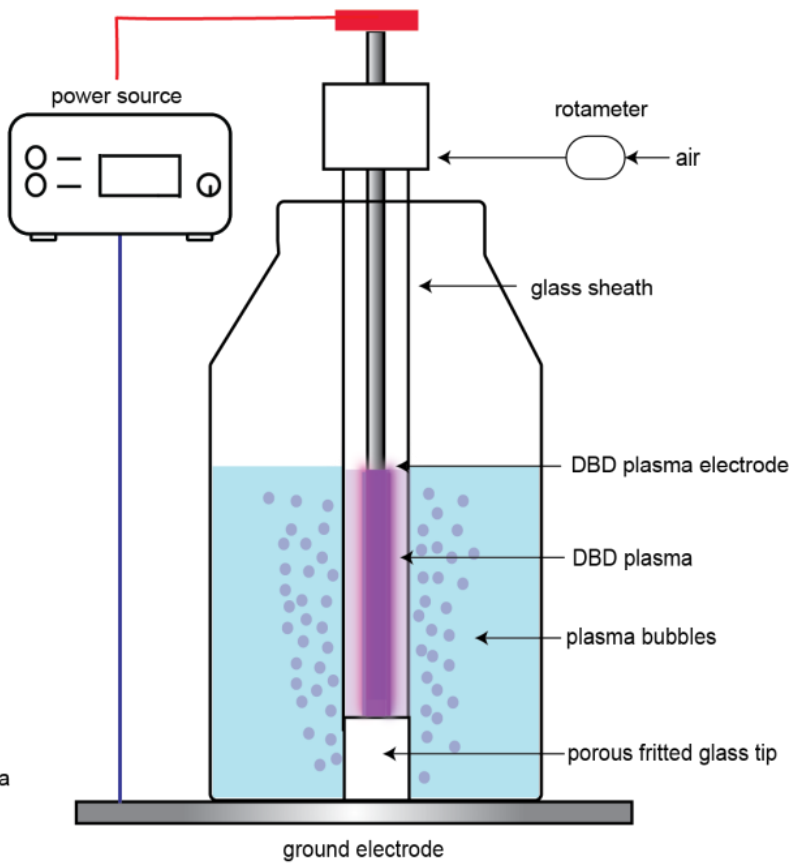

473 Figure 1. Schematic of the bubble spark discharge (BSD) reactor a) and the dielectric barrier discharge diffusor

474 (DBDD) reactor b) for PAW production.

475

476

Table 1. Bacterial isolates subjected to PAW treatments

\begin{tabular}{|l|l|l|l|}
\hline Bacterial Species & Strain designation & Serotype & Source (Year) \\
\hline Listeria innocua & $\begin{array}{l}\text { ICMPR:80-16-328-5025 } \\
\text { (non pathogenic) }\end{array}$ & - & Environmental (2017) \\
\hline Listeria monocytogenes & ICPMR: 07-15-147-1471 & $4 \mathrm{~b}$ & Ascetic Fluid (2015) \\
\cline { 2 - 4 } & ICMPR: 80-13-220-4103 & $1 / 2 \mathrm{~b}$ & Blood (2013) \\
\hline Escherichia coli & $\begin{array}{l}\text { ATCC R25922 } \\
\text { (non pathogenic) }\end{array}$ & $\begin{array}{l}\text { (Migula) Castellani } \\
\text { and Chalmers 1919 }\end{array}$ & Human clinical isolate (1977) \\
\cline { 2 - 4 } & ICMPR: 40-16-302-2227 & O157:H7 & Faeces (2016) \\
\cline { 2 - 4 } & ICMPR: 80-16-270-5374 & O26: H11 & Faeces (2016) \\
\hline $\begin{array}{l}\text { Salmonella enterica subsp. } \\
\text { Enterica }\end{array}$ & ICMPR: 06-17-184-1802 & Saintpaul & Faeces (2017) \\
\cline { 2 - 4 } & ICMPR: 80-17-173-5603 & Hvittingfoss & Faeces (2017) \\
\hline
\end{tabular}

477 


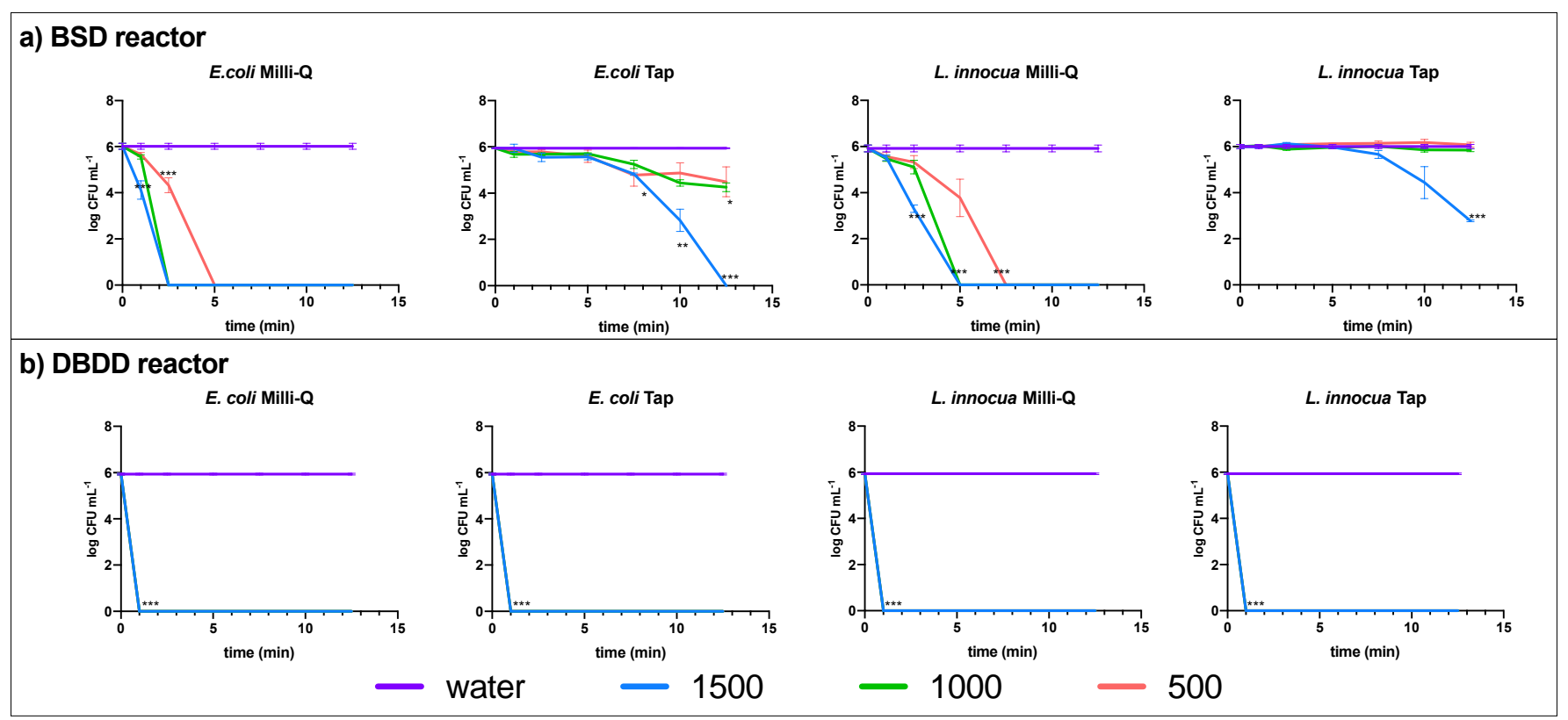

481 Figure 2: Reduction of bacterial CFU using the BSD reactor a) or the DBDD reactor b) with three discharge

482 frequencies over 12.5 minutes. A p-value of $<0.05$ was considered statistically significant.
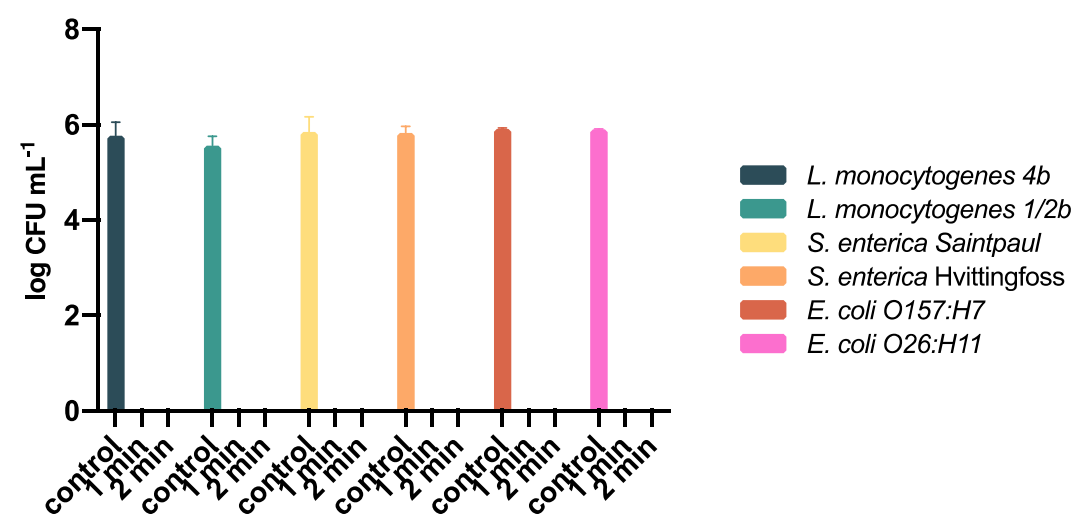

time $(\min )$

Figure 3: Complete reduction of pathogenic bacterial species is achieved using the DBDD reactor with 

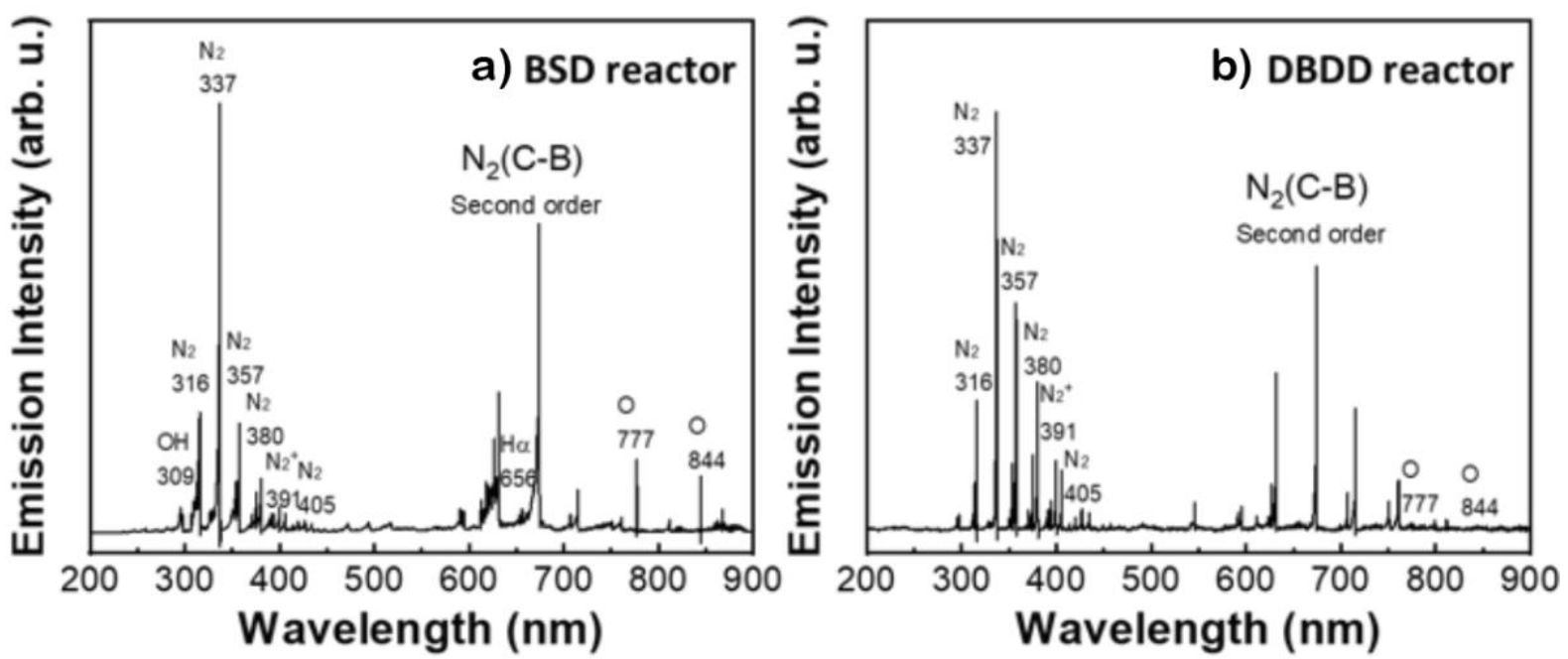

486

487 Figure 4. Optical emission spectra of the a) BSD and b) DBDD reactors measured using optical fiber indicated

488 the presence of reactive nitrogen and oxygen species in the plasma that they generated. 


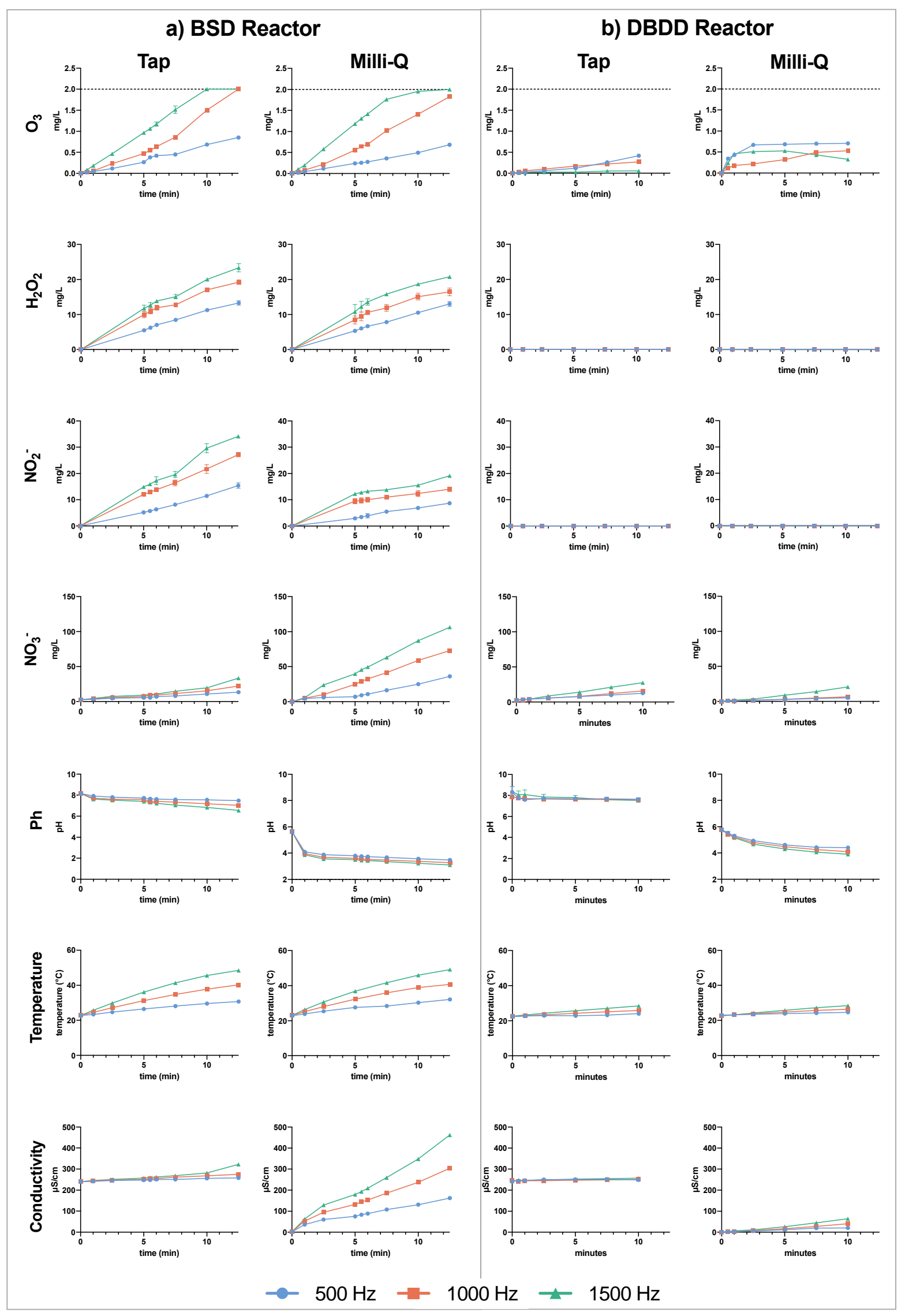

Figure 5. The concentration of reactive species present in PAW produced by the BSD reactor a) and DBDD

492 reactor b) using either tap or milli-Q water and run over a 12.5 minute time course. Higher concentrations and a 
493 more complex mix of reactive species was observed in the BSD-PAW. Reactive species generally increased

494 linearly over time, with higher discharge frequencies mostly leading to higher concentrations of reactive species

495 in the PAW generated by both reactors.

496

\section{a) BSD Reactor}
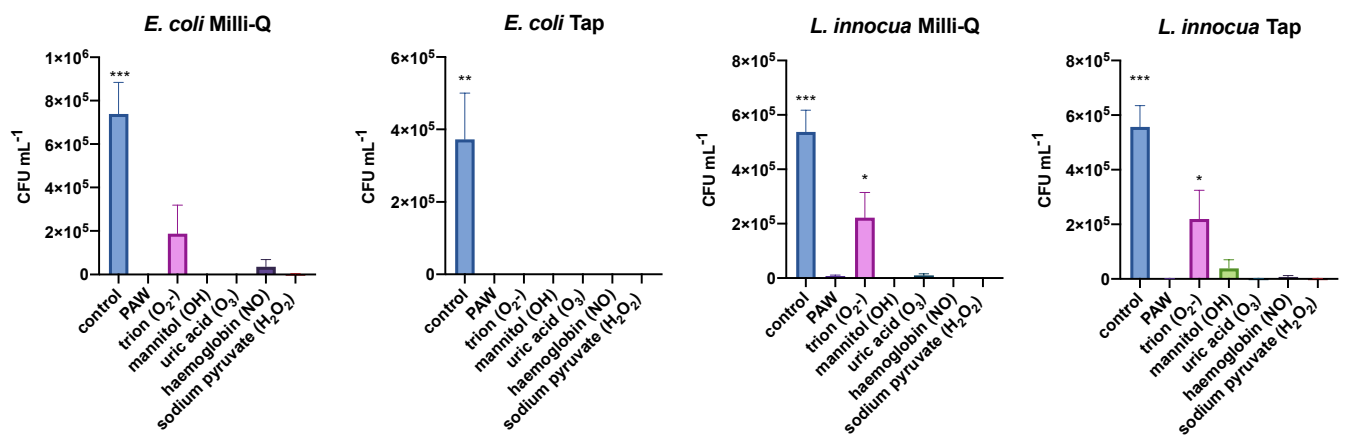

\section{b) DBDD Reactor}

497
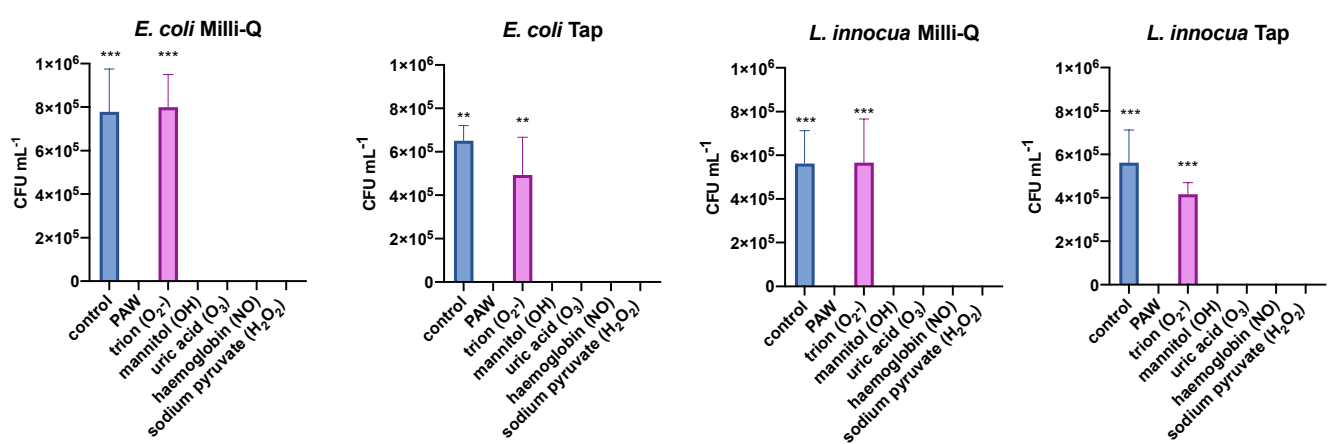

498 Figure 6. Addition of reactive species scavengers altered the antimicrobial efficacy of BSD-PAW a) and

499 DBDD-PAW b). The addition of the superoxide scavenger trion led to increased survival across most of the

500 treatments, but for BSD this only reached statistical significance with L. innocua treatment. None of the other scavengers led to increased bacterial survival. 


\section{Supplementary data}

\section{Tap water analysis}

\begin{tabular}{|c|c|c|}
\hline Sample & Units & Concentration \\
\hline \multicolumn{3}{|l|}{ Miscellaneous Inorganics } \\
\hline $\mathrm{pH}$ & $\mathrm{pH}$ Units & 7.6 \\
\hline Electrical Conductivity & $\mu \mathrm{S} / \mathrm{cm}$ & 220 \\
\hline Total Dissolved Solids (grav) & $\mathrm{mg} / \mathrm{L}$ & 140 \\
\hline Fluoride, $\mathrm{F}$ & $\mathrm{mg} / \mathrm{L}$ & 1.1 \\
\hline Nitrate as $\mathrm{N}$ in water & $\mathrm{mg} / \mathrm{L}$ & 0.48 \\
\hline Nitrite as $\mathrm{N}$ in water & $\mathrm{mg} / \mathrm{L}$ & 0.017 \\
\hline \multicolumn{3}{|l|}{ Ion Balance } \\
\hline Calcium - Dissolved & $\mathrm{mg} / \mathrm{L}$ & 16 \\
\hline Potassium - Dissolved & $\mathrm{mg} / \mathrm{L}$ & 3.4 \\
\hline Sodium - Dissolved & $\mathrm{mg} / \mathrm{L}$ & 15 \\
\hline Magnesium - Dissolved & $\mathrm{mg} / \mathrm{L}$ & 6.0 \\
\hline Hardness & $\mathrm{mgCaCO} 3 / \mathrm{L}$ & 64 \\
\hline Hydroxide Alkalinity $\left(\mathrm{OH}^{-}\right)$as $\mathrm{CaCO}_{3}$ & $\mathrm{mg} / \mathrm{L}$ & $<5$ \\
\hline Bicarbonate Alkalinity as $\mathrm{CaCO}_{3}$ & $\mathrm{mg} / \mathrm{L}$ & 50 \\
\hline Carbonate Alkalinity as $\mathrm{CaCO}_{3}$ & $\mathrm{mg} / \mathrm{L}$ & $<5$ \\
\hline Total Alkalinity as $\mathrm{CaCO}_{3}$ & $\mathrm{mg} / \mathrm{L}$ & 50 \\
\hline Sulphate, SO4 & $\mathrm{mg} / \mathrm{L}$ & 9 \\
\hline Chloride, $\mathrm{Cl}$ & $\mathrm{mg} / \mathrm{L}$ & 26 \\
\hline Ionic Balance & $\%$ & 2.0 \\
\hline \multicolumn{3}{|l|}{ HM in water - dissolved } \\
\hline Iron-Dissolved & $\mu \mathrm{g} / \mathrm{L}$ & $<10$ \\
\hline \multicolumn{3}{|l|}{ HM in water - total } \\
\hline Arsenic-Total & $\mu \mathrm{g} / \mathrm{L}$ & $<1$ \\
\hline Cadmium-Total & $\mu \mathrm{g} / \mathrm{L}$ & $<0.1$ \\
\hline Copper-Total & $\mu \mathrm{g} / \mathrm{L}$ & 400 \\
\hline Lead-Total & $\mu \mathrm{g} / \mathrm{L}$ & $<1$ \\
\hline Iron-Total & $\mu \mathrm{g} / \mathrm{L}$ & 11 \\
\hline Manganese-Total & $\mu \mathrm{g} / \mathrm{L}$ & 6 \\
\hline
\end{tabular}


bioRxiv preprint doi: https://doi.org/10.1101/2021.07.14.452435; this version posted July 15, 2021. The copyright holder for this preprint (which was not certified by peer review) is the author/funder. All rights reserved. No reuse allowed without permission. 